\section{Introduction: Expressions of the Soul ${ }^{1}$}

When the Japanese make declarations of love, they place their hand not on their heart but on their belly. They are sure that the soul resides in the stomach. This is why they perform hara-kiri, to set the soul free-which is a rather torturous way to reassure yourself of your own metaphysical being.

A Westerner, when talking about spiritual matters, might thump himself on the chest. If he does, he might feel, in the breast pocket of his coat, a Parker pen, a handkerchief, or even a billfold. ${ }^{2} \mathrm{He}$ won't find his soul, though, which lies three buttons below. You can grow accustomed to any geographic distance: longitude, latitude, altitude. But the umbilical cord, which ties a man to his home, naturally connects to the stomach, not the heart. Hearts may differ across the world. But no one can dictate to the stomach. Try to explain to the stomach, for example, that avocados are for eating and not just for decoration. ${ }^{3}$

The threads that tie a man to his homeland are many and varied: a rich culture, a mighty people, a glorious history. But the strongest threads stretch from the homeland to the soul. That is to say, to the stomach. These are not mere threads but more like ropes, Manila ropes. You can argue about culture, ethnicity, and history until morning, but can there really be any controversy about dried fish? ${ }^{4}$

They say you can't bring your country with you on the soles of your boots, ${ }^{5}$ but you can bring crabs from the Far East, spicy Tallinn anchovies, store-bought layered

\footnotetext{
The original Russian, Dushi prekrasnye poryvy, is quoted from Pushkin's ode "To Chaadaev" (1818): "My friend, let us dedicate to our country the beautiful outpourings of the soul!" Pyotr Chaadaev was a member of the Tsar's bodyguard in the Napoleonic Wars. After his resignation, he wrote a number of "Philosophical Letters," which criticized Russian culture. Nicholas I declared him insane in 1836. This is thought to be the first use of a diagnosis of mental illness to discredit a critic of the government in Russia.

2 This translation modifies the "white man"/Japanese contrast of the original; the importance lies in the exoticism of Japanese cultural markers such as hara-kiri. Russians are perhaps closer to the "East"; at any rate, they value the "soul" in a way that Westerners do not. The everyday details here are striking, and the Parker pen is important. In the authors' childhoods a ballpoint pen-especially one that wrote smoothly-would have been a luxury. However, does anyone actually carry a billfold in his breast pocket?

3 An avocado was quite an exotic food in the Soviet Union, one that must have seemed utterly improbable to new émigrés to America.

${ }^{4}$ Dried fish, vobla, here evokes Russian drinking parties where beer is the preferred accompaniment to this appetizer. Russians are tied together by their eating and drinking habits, and differing opinions about other matters pale in comparison to solidarity on this front.

5 This expression, attributed to French revolutionary Georges Danton (1759-94), dates to the late eighteenth century, considerably before today's border control concerns about whether visitors have been on a farm or in a pasture while abroad.
}

xi
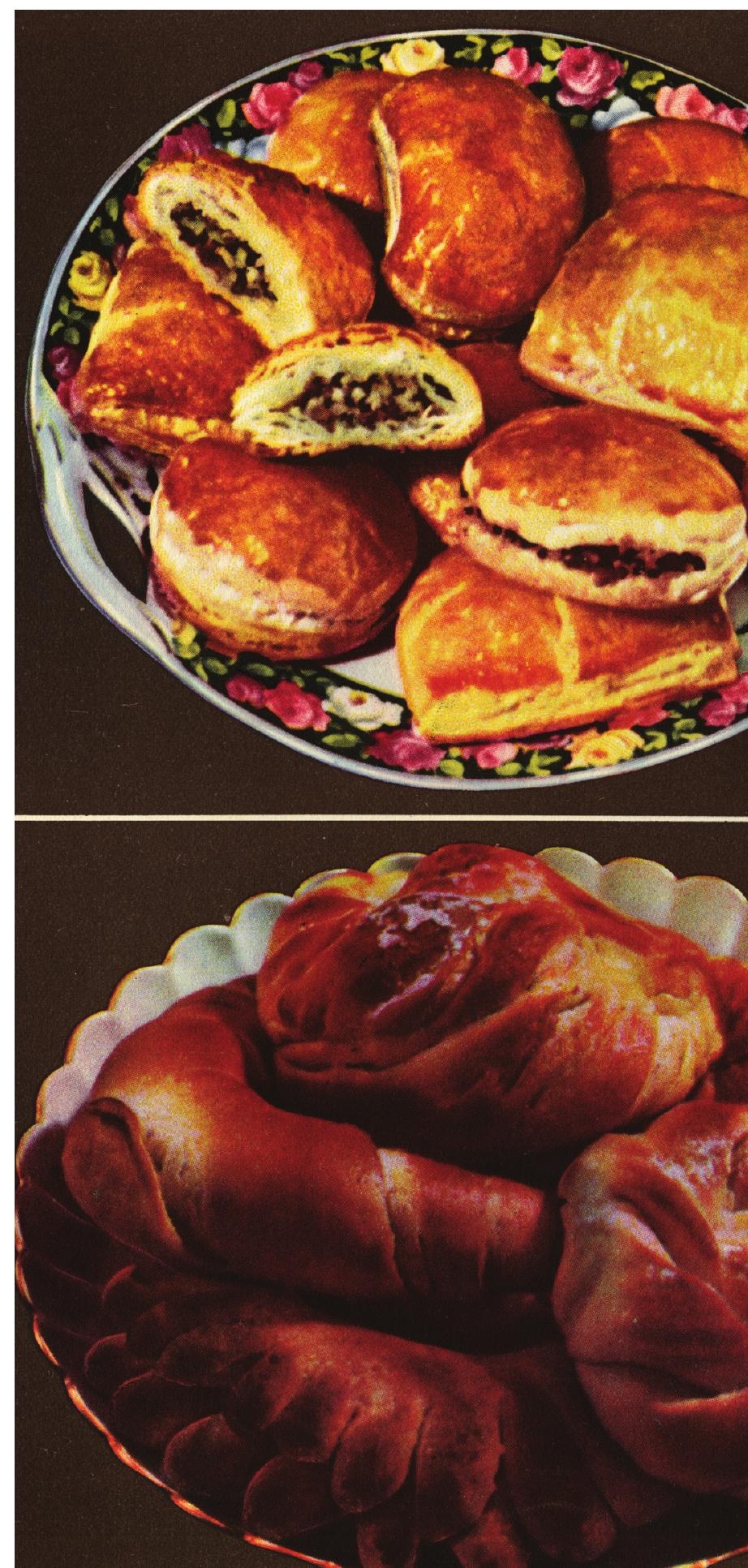
wafer cakes, "Bears of the North" chocolates, and bottles of Essentuki artesian mineral water (the best is No. 17). A shopping list like this (plus hearty Russian mustard) makes living in an alien land (ooh, and unrefined sunflower oil) better (don't forget those tangy little tomatoes) and more joyful (and round it out with some six-star Ararat cognac). ${ }^{6}$

Of course, even with a spread like this there will still be room at the table for nostalgic memories. Suddenly, with a puff of pink smoke, out swims an aspic costing 36 kopeks, then piroshki with "jam," then "borscht b/m" (b/m means bez miasa, without meat, nothing indecent). ${ }^{7}$ Also-hot greasy meat patties, bloody roast beef, Strasbourg pie. However, pardon, we've moved from nostalgia straight to the classics. ${ }^{8}$ As the prophet of our own scandalous generation, Venichka Erofeev, said, "We are given only one life, and it's necessary to live it so as not to make mistakes in recipes."

Our recipes, naturally, are not taken from the Larousse Gastronomique culinary encyclopedia, ${ }^{10}$ but they do have one undeniable advantage: they are ours, assembled by the collective mind of the masses and imbued with the spirit of the nation. Can we really leave all that behind? ${ }^{11}$ There will always be vegetarians and atheists who assert that the soul does not exist. ${ }^{12}$ But, then, why should we bother with people for whom nothing is sacred?

${ }^{6}$ This sounds like a conversation between the two authors-one, trying to stay on topic, while the other keeps adding more items to the imagined shopping list. "Better and more joyful" evokes the Stalinist maxim: "Life has become better, comrades, life has become more joyful." The juxtaposition of this Stalinist phrase associated with multiethnic bounty (as advertised and promoted, for example, in the 1939 Book of Healthy and Tasty Food) onto the émigrés life "in an alien land" makes a good introduction to this book of recipes and essays-nostalgic, but always playful. The shopping list features the flavors of a pan-Soviet diet: Essentuki is in Southern Russia, near the Caucasus mountains, but Ararat cognac comes from Armenia. "Northern" chocolates, far Eastern crabs, and Estonian anchovies mean this list contains every point of the compass across the vast Soviet empire.

As part of medical testing during the resettlement process, Russians-like all immigrants to the United States-were subjected to conversations with doctors and interpreters about b.m. (bowel movements). My own experience explaining about taking samples "cherez stul" (or every other b.m.) led to embarrassment and hilarity in sparsely furnished refugee apartments in the late 1980s. Among other things the Russian translation, cherez stul, sounded like I was asking the refugees to jump over kitchen chairs [AKB].

8 These first items are all "proletarian" or everyday items one might find in a Soviet factory or school cafeteria, whereas the last two, "bloody roast beef" and "Strasbourg pie," are upper-class food items from Alexander Pushkin's 1820s novel-in-verse Eugene Onegin. Russians of the late Soviet period would know these lines, both because of the culturally conditioned habit of learning vast stretches of Pushkin's novel by heart, and because these dishes were so exotic as to be unattainable and even unimaginable in the Soviet era. We can see the logic as the "hot, greasy meat patties" lead directly into the "bloody roast beef" - but for a Russian reader, the other (also unattainable in the Soviet era) items on Pushkin's dinner menu would also be hovering in his mental background as he read: truffles, pineapple, Limburger cheese. See Eugene Onegin, chapter 1 , verse XVI.

9 The transition directly from the "poet-prophet" of the nineteenth century into the underground "prophet" of Soviet dissident culture indicates that the reader should take Venedikt Erofeev's alcohol-infused 1969 novel Moscow to the End of the Line (sometimes translated as Moscow's Stations) seriously as a vital cultural text. This quote from Erofeev's novel is a parody of another famous line from Nikolai Ostrovskii's classic Socialist Realist novel How the Steel Was Tempered (1936), spoken by his protagonist Pavel Korchagin: "We are given only one life, and it's necessary to live it so as not to feel excruciating pain about aimlessly lived years, so as not to feel burning shame about a miserable and trivial past and so that, dying, we can say: All my life and all my strength were devoted to the most wonderful thing in the world- the struggle to free mankind." The Pavel Korchagin line was memorized by all Soviet schoolchildren and was supposed to serve as a moral guide to how they lived their lives; Erofeev's line gives them a different message, a suggestion that they drink heavily, concocting more and more new and cheaper cocktails, which would help to obliterate the effects of official propaganda all around them.

10 Both an important culinary artifact and, again, something very exotic to the Russian ear. The Larousse might evoke $a$ la russe to someone unfamiliar with the name, but the next word in French, gastronomique, makes it clear that the homonym is only a coincidence.

11 The "collective mind of the masses" and the "spirit of the nation" are Soviet clichés, but the authors' reluctance to part with them underscores the degree to which Soviet culture remained essential to those who chose to emigrate. And, of course, like many of V\&G's borrowed expressions, these clichés drip with irony in their new usage.

12 The "b/m" [without meat] in the previous paragraph indicates a cheaper soup for a student budget, although its precedent would have been a "fasting" version of beet soup for those who followed Russian Orthodox dietary restrictions. In the Soviet context, diners could not admit to following a religious diet, and yet vegetarianism for V\&G is, as we see here, an abomination. So where does religious feeling inhere? Clearly for V\&G, it is to be found in cuisine. 